\title{
Contract Areas and Service Quality Issues in Public Transit Provision: Some Thoughts on the European and Australian Context
}

David A. Hensher, The University of Sydney

Abstract

The introduction of contract regimes for the provision of bus services, such as competitive tendering ${ }^{1}$ and performance-based contracts, is usually premised on a prior assumption that the size of the physical contract area is given and that any policies related to interactions between contract areas, such as integrated ticketing and fares, ${ }^{2}$ are agreed to. This article examines the evolving arguments th at encourage $a$ review of contract area sizes before recontracting and the positions supporting the benefits of service quality-related issues such as an integrate $d$ fares policy. Given that a growing number of analysts (especially in Europe and Australi a) are promoting the appeal of increasing physical contract area size to facilitate, among other reasons, an integrated fare regime, it is timely to explore the pros and cons for such reform to ensure that they are not counterproductive to the desired outcomes of a reform process. The arguments presented here caution the support for too small a number of large contract areas on grounds of internal efficiency losses and limited gains in network economies (but support amalgamating very small contract areas). Existing 
empirical evidence, limited as it is, tends to support contract areas (and depots) currently serviced by fleet sizes in the range 30 to 100 regard less of urban development profile. Alternative ways of delivering cross-regional and broad-based network benefits are proposed.

\section{Introduction}

Reform of the bus sector in many countries has focussed on alte rnative service delivery regimes such as competitive tendering ${ }^{3}$ and performance-based quality contracts (see, for example, Hensher and Stanley [2003] and Pre ston and van de Velde [2002] for details). Two issues that arise when detailing specific reform strategies are the geographical definition of the service area (or e ven whether it is a single route as in London) and the flow-through implications of service quality initiatives such as integrated fares. ${ }^{4}$ The latter relates to the ability of a passenger to travel between public transport modes and operators on a single fare as well as potentially offering time savings. ${ }^{5)}$

In developing an implementation plan for performance-based cont racts (such as the one developed by Hensher and Houghton [2003]), a number of commentators have raised the question of how many contracts should best be provided within a particular geographical setting. Should we take the existing contracts (and areas) or rationalize the contracts to a smaller number? Arguments proposed for fewer contract areas are mainly related to administra tive coherence and passenger benefits from network integration. A concern with fewer contracts (depending on the meaning of "fewer") is the potential loss of internal efficiency and the high risk of monopoly power and/or market dominance, with resultant pressures on government to increase subsidies beyond what currently exist and/ or are in any sense optimal.

This article examines the arguments for and against a range of reform initiatives associated with the determination of the geographical size of contract areas, as well as revenue allocation and patronage benefit issues linked to integrated fares associated with cross-contract service delivery. Although the article focuses on Australia (Sydney in particular), and to a lesser extent Europe, to illustrate some of the evidence, the arguments presented are of relevance universa lly and are especially useful for the United States, which appears to lag behin d the reform programs of Europe and Australia. ${ }^{6}$ 


\section{Contract Area Size and Number}

The problem is that individual firms in the transportation industries provide service only over limited portions of a network, but [some] customers' demands extend over the entire network. The necessity of providing through ... service from any origin to any destination requires cooperation among firms who are also expected to compete in the new environment of regulatory reform. These industries have been regulated in the past precisely to deal with the 'interconnect' and 'competitive access' issues. But the [competition policy] laws generally presume that firms should compete [in a potential if no actual sense], not cooperate. (Tye 1987: xviii)

Is there such a thing as an optimal contract area size in a geo graphical sense? What criteria might one apply to decide on this? Presumably the answer relates to demand-side considerations, such as network connectivity impacts (economies of scope through networks, integrated fares, etc.), and the supply-side, in terms of cost and service delivery efficiencies. It is not dissimilar to the arguments on the optimal number of firms in an industry. ${ }^{8}$

There are two issues (at least) to address: (1) what likely changes in network service delivery are desired and can be achieved by amalgamating contract areas that cannot be achieved by alternative strategies, such as establish ing network alliances (even incentive-based ones ${ }^{9}$ ) within the existing contract area regime; and (2) will such amalgamations lose the internal (to an operator) efficiencies that currently exist and which promote sufficient observations for benchmarking performance? How many contract areas are appropriate? Preston and van de Velde (2002) comment that the $\mathrm{U}$-shaped subsidy profile detected over time in competitive tendering is, in part, due to the winner's curse ${ }^{10}$ but more importantly in the current context, in part, due to excessive concentration or collusion. The upping of prices in rebids is becoming common (as observed in Europe in particular) as the number of bidders drops (as a result of fewer operators in the mar ket). Contract area size is a feature of the literature on spatial monopoly where e ach contract area may be in the hands of a few operators who are able to collude acti vities across contract areas under their control. By amalgamating contract areas this is tantamount to the same implications for efficiency (albeit legally) as collusion.

The trade-offs between network/demand economies and internal efficiency will depend on a number of structural and historically contingent ch aracteristics in- 
cluding such different aspects as urban development and operato $r$ culture (Carlquist 2002). This was certainly true in the Sydney context in the early 1990s when the NSW 1990 Passenger Transport Act was introduced. It defined a suite of 78 contract areas based primarily on incumbency (tantamount to grandfather rights). Since then the number of operators has been reduced, $w$ hile the contract areas have remained in tact. New global operators have moved in to Sydney (e.g., National Express from the United Kingdom, Connex and Transdev from France) looking for opportunities to expand in the Australian market. Where geographically adjacent operators have been willing to sell, in part due to pressures to sell from the large global operators, but also because of the percei ved uncertainty of the new reform agenda (under discussion in 2003 but without a direction to date), there is evidence of larger service areas under one oper ator (strictly the same contract areas as before but now bringing a capability of cross-contract operations).

The State Transit Authority of New South Wales (STA), the government-owned operator, is the largest operator with 26 contracts and runs the public bus network which covers almost half of Sydney (1.6-1.8 million popula tion, nearly 800 square kilometres, and 1,750 buses operating out of 11 depots) centered on the Sydney CBD (See Figure 1). It has many adjacent contract areas so that its services are not delivered on a contract area basis per se, operating as one very large provider. The STA has designed a route network of services that takes passengers to key centers across a region, not just within the contract area. This network economy is achieved, however, at a relatively high internal inefficiency cost of $\$ 4.86$ per bus kilometer ${ }^{11}$ (in contrast to the best practice cost of $\$ 2.60 /$ bus kilometer for private operators who currently have 53 contracts among 30 operators). The important question herein is the extent to which the cross-contract area service provision has contributed to these higher unit costs or whether it is the product of government ownership and specific restrictions of service delivery. Part can be attributed to externalities such as traffic congestion. Based on the STA's operations outside of the Sydney Metropolitan Area (in Newcastle, a regional Center $120 \mathrm{kms}$ from Sydney with a population of about 500,000 ), we could reduce the $\$ 4.86$ to $\$ 3.54$ (Daniels 2002). However internal inefficiency must account for much of the remaining increment above $\$ 2.60$. 
Figure 1. The Sydney Metropolitan Area and the STA Contract Area

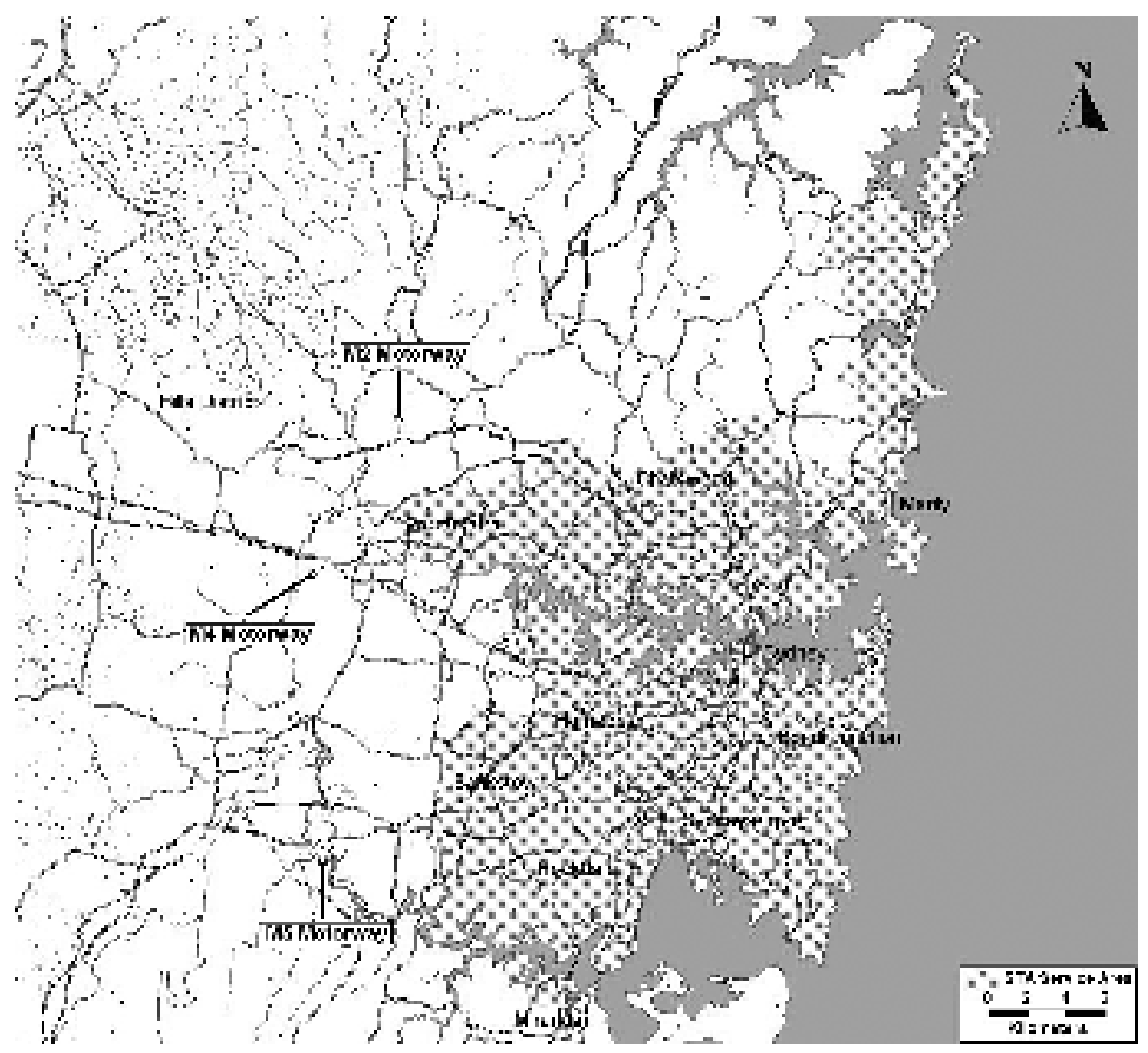


The literature on industrial organization from which ideas cent ral to tendering evolved such as principal-agent relationships, transactions costs, and economies of scale and scope, puts forward compelling arguments that many of the gains in service delivery to the market can be effected through preservation of smaller effective management units working within a range of alliance structures, where each alliance is established to best accommodate the interests of the market (i.e., customers) and the interests of the supplying stakeholders (see Hay and Vickers [1987] and Williamson [1987]). To assume that one large organization with a single large contract area (or even a few under an oligopoly) is the best way forward in servicing the market is questionable. It assumes that the transactions costs between operators and customers are excessive and the transactions costs within an organization are nonexistent or minimal ${ }^{12}$. Indeed the literature on the economic theory of regulation (or "capture" theory) describes how regulatory agencies may end up more or less in the pocket of those whom they purport to regulate. The response in some industries has been the dismantling of such regulatory frameworks through economic deregulation (e.g., airlines, telecommunications), with a replaced regulatory regime focused on monitoring.

There is an analogous literature arguing for local specialization and alliances instead of the formation of large, single-entity businesses. Inde ed, it does not take long before we see many of the very large entities essentially operating as a set of separate entities with occasional cross-subsidy to facilitate short-run (at least) viability across the entire set of organizations under the one control. This breeds inefficiency (like governments bailing out their own public mon opolies) and upward pressures on subsidy support from government. As Preston and van de Velde (2002) state "...governments caving in to operators suffering from the winner's curse or generally finding life tough was a real threat to competitive tendering in some countries and situations."

Fundamentally, the reduction in the number of contract areas runs the risk of further promoting dominance and a further move away from the ideals of competition policy. ${ }^{13}$ It is a dangerous move if it erodes the competitive base of the bus market in the sense that it reduces the ability to promote and maintain a process of effective or potential competition so as to achieve a more efficient allocation of resources. ${ }^{14}$ In large measure, we have to put to the test the case that suc $h$ amalgamations deliver additional benefits that more than outweigh the additional costs. 
However alliances do not just happen. The market may well send signals to encourage such alliances but there is no guarantee that the signa ls will be registered and acted upon. To ensure market signal activation, appropriate information and incentives need to be put in place. Government, through its regulatory agency, can make a major contribution to this process. In the presence of imperfect information, signaling and incentive systems are at the center stage. To date in most international settings where regulatory reform is active, there is little evidence of alliances (although see Norway in the next paragraph), which is disappointing, but this may well be explained by the strategic intent of the $\mathrm{n}$ ew (global) players and the lack of incentives in the past. The evolution of allian ces will require much more incentive-driven initiatives by the regulator especially where there is a loss of internal efficiency due to the scale of operations. There is no denying that this happens, but what is important is the size of an operator beyond which such internal efficiencies come into play. In Sydney, for example, where most recent purchases involve operators controlling more than 100 buses, these are worrying signals (see evidence below).

There is an interesting history of cooperation and merger in Bergen, Norway (Carlquist 2002). Although a merger attempt between the two major operators failed in the early 1990s, it led to substantial route and fare cooperation. In 1998 a new merger attempt succeeded. Furthermore, all bus companies in the region already cooperated in an alliance regarding electronic ticketin g fare coordination and purchasing. It was, therefore, easy for the regional public transport authority to impose a requirement for integrated fares in the performance contract, initiated in 2000. The operators were obliged to have a common ticke ting system and fare tariff, but there is no limit to the upper fare level. The re is no evidence to support (or falsify) the existence of new patronage attraction or increased benefits to existing passengers, although Carlquist (2002) suggests that the latter is more likely than the former. In either case, it would be difficult to hypothesise that a "successful" integration was due to regulatory intervention, as a successful alliance between the operators already existed.

Whether by amalgamation of ownership or alliance formation, the se are both merger phenomenon. For example, combining three contract areas into one area is a (horizontal) merger and should be assessed along the same lines as the merger of two organizations. If there are economies of scale (for the exact same service type), then there are efficiency gains. The realization of these gains, however, could be offset by welfare losses due to reduced competition, be it a ctual or yardstick, in 
the case of either competitive tendering or performance-based contracts (the latter during the contract period in competing for incentive payments, the former at the time of bidding). DeBorger and Kerstens (2000) review the evidence and conclude overall that there are no economies of scale but mild economies of scope associated with demand complementarities where the evidence suggests spatial demand exists beyond contract/operator areas. The latte $r$ is an empirical issue. It is investigated below for Sydney where there is very little intercontract area use of public transport but opportunities for cross-regional services capable of being delivered efficiently by a single operator. Indeed, as organizations increase in size, they lose the relative precision required to establish the value of specific activities; in contrast, through alliances there is much more precision and transparency. A synthesis of some key themes is given in Table 1.

\section{Table 1. Synthesis of Key Issues in Determining Optimal Size Operator/Contract Area}

\begin{tabular}{|c|c|}
\hline Theme & Comments \\
\hline $\begin{array}{l}\text { Density of route network } \\
\text { and network economies }\end{array}$ & $\begin{array}{l}\text { - As it increases, there is operational dependency on availabil- } \\
\text { ity of fixed facilities (central depot, local terminal...) } \\
\text { - Very high fixed costs of depots which require sharing of these } \\
\text { costs } \\
\text { - Presence of such high costs involves a trade between sharing } \\
\text { costs over many more activities/services, risks of diseconomies } \\
\text { of scale and elimination of potential competition (either lead- } \\
\text { ing to entry under deregulation or competitive tendering or } \\
\text { competition for incentive payments under PBC) }\end{array}$ \\
\hline Route Structure & $\begin{array}{l}\text { - The balance between degrees of hubbing ranging from hub- } \\
\text { dominated to more uniform distribution in urban area moves } \\
\text { to latter as a continuous spatial diffusion of urban activities } \\
\text { takes place }\end{array}$ \\
\hline Demand complements & $\begin{array}{l}\text { - Attributes of individual services as demand complements } \\
\text { means that a change in frequency (say) of one service affects } \\
\text { the demand for another }\end{array}$ \\
\hline Internal efficiency & $\begin{array}{l}\text { - Delivering services under benchmarked best practice in re- } \\
\text { spect of cost efficiency, cost effectiveness, and service effec- } \\
\text { tiveness }\end{array}$ \\
\hline
\end{tabular}




\section{The Theoretical Argument}

The relevant literature on the optimum number of firms in a market focuses on the cost and performance structure of each firm both in respect of the supply of services and the welfare benefits to passengers of a specific s upply regime. Evidence of scale and scope (especially network economies) is an important basis for commenting on the appropriate number of operators (and hence contracts).

Transaction cost economics (TCE) provides an appealing framework within which to develop the arguments for the roles of the market and governance. A transaction occurs when one stage of activity finishes and another beg ins. With a wellworking interface these transfers occur smoothly. Establishing a smooth transfer is what network economies (including integrated fares) are all about. Their achievement is possible through a number of strategies such as alliance contracts and merger (see the Bergen experience cited above). TCE supplants the usual preoccupation with technology and distribution costs, with an examination of the comparative costs of planning, adapting, and monitoring task completion under alternative governance structures. It is as much about transact ions within a single entity (e.g., one bus operator, a regulator) as it is between entities. It pays special attention to information signaling and processing (and its asym metry throughout the system), bounded rationality (i.e., the ability to proc ess a limited amount of information), hazard, opportunism, and asset specificity.

Transaction cost economics maintains that it is impossible to concentrate all of the relevant bargaining action at the ex ante contracting stage (which is what competitive tendering essentially does). Instead, bargaining is pe rvasive in which case the institutions of private ordering and the study of contracting in its entirety take on critical economic significance. Performance-based contracts (PBCs) align with this view (see Hensher and Stanley 2003) since the market opera tes actively throughout the contract period (under signals delivered through incent ive payments). The behavioral attributes of human agents, whereby conditions of bounded rationality and opportunism are joined, and the complex attributes of transaction with special reference to the condition of asset specificity, are responsible for this condition (Williamson 1987: 178). Alignment of incentives is ce ntral to efficient contracts and property rights. The latter emphasises that ownership matters, with rights of ownership of an asset defined as the rights to u se the asset, the right to appropriate returns from the asset, and the right to change the form and/or substance of an asset. 
Transaction cost economics acknowledges merit in both monopoly and efficient risk-bearing approaches to contract. It insists, however, that efficiency purposes are sometimes served by restraints on trade. (Williamson 1987:188). This statement by a pioneer of transactional economics, $X$-efficiency, and contracting theory, is crucial to the discussion because it puts forth the argument that examination of the underlying attributes of transactions discloses that restraints on trade can help to safeguard the integrity of transactions when firm-speci fic investments are at hazard.

\section{Evidence on Cost Savings from Scale of Operations}

One useful analysis to establish the potential gains for larger operations (which also means larger contract areas and hence less operators) is to look at the evidence on performance outcomes when tendering for different size bids. A caveat: The great majority of the empirical evidence focuses on operational cost savings and little about the true costs of conducting tendering and mon itoring etc. The competitive tendering of a large public sector provider delivers an immediate cost saving but it is a once-only gain. ${ }^{15}$ This gain is greater when the pretendered unit is large (as in most government-owned bus operations, such as occu rred in London in the 1980s and 1990s) and it is being tendered out as a set of smaller contracts. Subsequent retendering of the smaller contracts, however, leads to very little cost savings if any. Indeed, the often-quoted cost savings up to 20 percent (net of administrative costs of tendering) do not shed light on the cru cial question as to what proportion of these savings can be attributed to competitive tendering per se. ${ }^{16}$ The switch to a smaller operator with lower fixed costs and overheads in itself, could achieve these savings regardless of the mechanism used to select the operator.

The main message is that savings increase as system size increases, which implies that if we move to larger contracts by operator merger (or buyouts by large players), we can expect increases in the costs of doing business. While this might not be disputed, the rebuttal is likely to come in terms of net work economies on the demand side. This is where we draw on transaction cost econ omics to assist, since even in the presence of economies of network integrity there are alternative ways of delivering optimal network performance without creating a small number of large and relatively inefficient contract areas. 


\section{Summary of the Main Argument}

In determining the appropriate size of contract areas, it is important to recognize both internal efficiency and external benefit arguments. Intern al efficiency arguments recognize the importance of the performance of the service delivery entity regardless of whether the objective is commercial or social obligation. Efficiency encompasses cost efficiency, cost effectiveness, and service effectiveness. External benefits focus primarily on accessibility and, in particular, the integrity of the network and associated network economies.

In considering the appropriate size of the service delivery unit (SDU), the costs of transaction are very important. These costs are not limited to the interfirm environment (which would include integrated fares and servicing of an interconnected network) but include the costs outlaid within a firm. An issue of relevance in achieving the efficiency and network benefits is the revealing of information through appropriate signals (either from the market or by the regulator) to ensure that the best information is acted upon to deliver service s to the market at cost efficient and effective levels that, within a subsidy-depe ndent environment, delivers best value for money (in an efficiency and equity sense) for the scarce subsidy dollar.

Looking at the internal efficiency of an SDU, the evidence from the published literature supports the view that there are no scale economies (over 100 buses) ${ }^{17}$ but mild network economies. ${ }^{18}$ The latter translates in particular into an argument for having fewer (or even one) SDU operating a network-bas ed crossregional service, since the argued benefits to passengers are greater than if the cross-regional services were provided by more than one operator. The assumption implicit in this evidence is that passengers would have to transfer between modes (or bus operators) to complete their journey. These network economies are relatively weak where cross-regional services are shown to be deliverable by smaller operators who move through other contract areas or where, through contract area alliances for specific routes, they can pick up a nd drop off passengers anywhere along the route.

A good example in Sydney of the former is the private operator, Forest Coaches, who has a service from St. Ives/Chatswood $(20 \mathrm{kms}$ north of the city in a very wealthy area) to the city; a good example of the latter is the $35 \mathrm{~km}$ orbital service about $5 \mathrm{kms}$ out from the CBD in Perth (Western Australia) operated through an alliance of three operators. This last example is equivalent to what Adelaide (South 
Australia) would refer to as a route-specific contract across contract areas (see Appendix 2). Creating a monopoly supplier to deliver the mild $n$ etwork economies is false economy since it will almost definitely lead to major losses in internal efficiency. Rather, given the evidence from the Transport Data Centre (TDC) of the NSW government that the majority of travel in Sydney occurs loc ally ${ }^{19}$ (mainly within one contract area but also between two adjacent contract areas), typically over 80 percent of all trips (often within a single contract area using a bus service locally or to access a rail interchange), the risk of delivering highly expensive local services to the majority of users just to satisfy a claim on ne twork economies for a small amount of patronage service delivery is poor economics. Indeed, encouraging longer trips by any form of transport seems inconsistent with a desire to curtail travel and promote more local activity.

An important message from the institutional economics literature is that we should focus on efficiency and not market power (the concern with reducing the number of contract areas); and we should not aggregate operators or contract areas just to gain network benefits in situations where most of these benefits are within an existing contract area in the main. Through recognition of market opportunities (using appropriate signalling methods to reveal and share information and hence reduce information asymmetry) created by partnerships bet ween all operators and government (via the regulator), and the formation of o perator alliances to serve specialised cross-regional market niches, the major transaction costs (e.g., information asymmetry) appear to be more than offset by the huge gains in internal efficiency associated with operators with contracts in the 30 to 100 fleetsize range. Importantly, an individual operator may have more than one contract (as many do), but there are sensible arguments to support the maintenance of each contract as a separate business center. Large operations, such as many Asianbased bus businesses (e.g., in Hong Kong), might benefit by reviewing their structures and may reduce the growing levels of subsidy support that, in part, funds inefficiencies.

\section{Integrated Fares: Regulatory Control and/or Genuine Benefit to Passengers?}

Do people need to use more than one mode of public transport/ operator to use public transport as an alternative to the car? Maybe the transfers associated with multi-modal movement are a major barrier regardless of what fare arrangements are in place? 
Integrated fares are seen as a way of attracting more public transport patronage because they enable one to purchase a multimodal and/or multiop erator ticket at one point in time from one source. Although there is initial appeal in this fare strategy, the justification must be based on an agreed set of objectives. The most important must be a benefit to passengers (and associated flow-through to operators and the community at large). It is assumed that one of the reasons why public transport is not used as much as it might is the poor in tegration of services across the network. One feature of poor integration is the need to purchase a separate ticket from each operator, which is assumed to be more expensive than the purchase of a single multimodal/operator fare because of the fixed-cost component in each ticket. The presumption is that there would be a single-fixed component in an integrated fare (although this needs to be demo nstrated).

Overriding the actual fare level is the issue of network integrity and what this actually means for passenger growth and benefit. What is the evidence that passengers actually want to travel by a number of public transport modes across a network if the modes were better integrated? What is the eviden ce that integrated fares is the solution (or even a significant contributor)? The counterfactuals would have to show that improved integration, on whatever criteria are adopted, would indeed show movements between modes and operators that are currently not able to be undertaken. The opportunity for such travel does exist in most cities (at least to some extent) in terms of services available, but is it what people want? Such a system leads to transfers and with greater dominance of a few o perators there is a real risk on hubbing whereby transfers become a negative featur e. The evidence in Appendix 1 from around the world initially looks compelling, but it must be interpreted very carefully. What exactly are we seeing-some sort of discount disguised through integrated fares and/or genuine contributions to improving mobility across the network?

To illustrate this matter, Table 2 shows the year 2000 evidence on public transport use in Sydney involving more than one public mode. The use of $\mathrm{m}$ ultiple public modes in 2000 is $\mathbf{1 7 . 4}$ percent. This table distinguishes the num ber of times in a trip that a specific mode is used. Of particular interest is the use of more than one bus for a one-way trip. Out of a total of 1.29 million daily passenger trips that involve at least one public mode in a trip chain, 2.861 percent of all trips (i.e., 36,982 trips) involve two or more buses. It might be argued that switching between buses highlights a downside of services that is better de livered through single-vehicle cross-regional services. The greater amount of the multiple-bus trips 
are on government buses $(31,508$ or $85.2 \%$ ) operating close to the CBD, which may say something positive about the ability to travel beyond contract areas by bus although it says something negative in respect of the requi rement to have to transfer. ${ }^{20}$

Table 2. Average Day Linked Trips Involving at Least One Public Transport Mode, HTS2000

\begin{tabular}{|c|c|c|c|c|c|c|c|c|}
\hline \multirow[b]{2}{*}{ Ferry } & \multirow[b]{2}{*}{ Private Bus } & \multirow[b]{2}{*}{ Train } & \multicolumn{5}{|c|}{ Public Bus } & \multirow[b]{2}{*}{ Total } \\
\hline & & & 0 & 1 & 2 & 3 & 4 & \\
\hline 0 & 0 & 0 & & 338,364 & 28,065 & 1,396 & 346 & 368,171 \\
\hline 0 & 0 & 1 & 446,502 & 72,852 & 3,229 & & & 522,583 \\
\hline 0 & 0 & 2 & 34,132 & 2,868 & & 197 & 235 & 37,432 \\
\hline 0 & 0 & 3 & 2,739 & 571 & 214 & & & 3,524 \\
\hline 0 & 0 & 4 & & 428 & & & & 428 \\
\hline 0 & 1 & 0 & 267,790 & 2,372 & & & & 270,162 \\
\hline 0 & 1 & 1 & 45,883 & 2,605 & & & & 48,488 \\
\hline 0 & 1 & 2 & 1,926 & 365 & & & & 2,291 \\
\hline 0 & 2 & 0 & 6,688 & & & & & 6,688 \\
\hline 0 & 2 & 1 & 2,471 & 132 & & & & 2,603 \\
\hline 0 & 3 & 0 & 1,397 & & & & & 1,397 \\
\hline 1 & 0 & 0 & 15,281 & 5,166 & 1,070 & & & 21,517 \\
\hline 1 & 0 & 1 & 2,574 & 1,044 & & & & 3,618 \\
\hline 1 & 0 & 2 & 1,252 & & & & & 1,252 \\
\hline 1 & 1 & 0 & 634 & 234 & & & & 868 \\
\hline 1 & 1 & 1 & 375 & & & & & 375 \\
\hline 2 & 0 & 0 & 1,055 & 159 & & & & 1,214 \\
\hline
\end{tabular}

Note: Data includes trips that may have used other (non- $T$ ) modes. The other modes are ignored; therefore one public bus may mean one public bus only or one public bus plus car. 
Interconnectivity involving more than one bus operator in Sydney is negligible (even if one argues this is due to relatively poor existing int erconnectivity) and is unlikely to be of concern to most of the traveling population. While it might be argued that the nature of the existing network of services deni es this opportunity (and certainly the counterfactuals are not available), if such network connectivity were to be provided and would increase patronage, the issue of relevance here is whether cross-regional and long-haul metropolitan services can be achieved under existing area contracts by appropriate alliances which preserve the efficiencies of each operator (including transaction cost advantages).

The recent growth in cross-regional services in Sydney by priva te operators without transfers demonstrates one useful counter-factual in which a passenger can travel on a single-mode/single-operator service without transfers over long distances within the Sydney Metropolitan area (to/from the CBD which is not owned by a single contract and an open-access service zone). Examples include the Westbus M2 and Hills services (in the northwest), Harris Park Citybus (from Parramatta in the west), and Forest Coaches St. Ives/Chatswood-City service (in the north), all of which serve the outer suburbs and deliver passengers into the $C B D$ (see Figure 1). ${ }^{21}$ Similar examples exist for the STA except that many of the STA services are across contract areas belonging to the STA enabling pick up and drop off across the contract areas (although one might argue that strictly this is violating the terms of a contract). The need for integrated fares in these ex amples (where public transport is showing evidence of serious competition with the car) is not relevant. $^{22}$

Integrated fares are a form of regulatory intervention if impos ed on all operators from above since all must conform to the grand plan. As Hibbs (2000) has indicated, constructs of integration (of which integrated fares are an example) lead to a weakening of both effectiveness and efficiency. It denies individual operators or groups of operators the full ability to be responsive to market opportunities in ways that are consistent with delivering the appropriate services to customers. Again, Hibbs and others argue that other than the regard for sa fety and issues of scale and power, public passenger transport is a market-based, customer-driver activity and especially with regard to its relationship with the private car, from where most of its competition comes. Integrated fares dictated across the board may well be inequitable as well as an inefficient way of securing optimum social benefit. ${ }^{23}$ Market-based fares policies designed to benefit users are need ed, and the best test of this is the levels of patronage resulting from the policy. If a specific 
arrangement or alliance between operators in a particular public transport chain sees merit in integrated fares, then this should be supported, but not as a carte blanche, no-choice policy. The "one-size-fits-all" philosophy is very dangerous and counterproductive.

\section{What Is the Broader Evidence on Patronage Benefits?}

The matter of integrated fares and impacts on patronage is not well studied. There are virtually no published papers on the topic that make the link clear and unambiguous. That is, unless one can separate out all the other cha nges that are happening at the same time (e.g., fare discounting), ${ }^{24}$ it is not possible to make any sensible statements on the specific contribution of integrated/intermodal/ interoperator fares.

In reviewing the literature we have found a number of comments that state that intermodal fares are often inappropriate where one has mainly mode-specific travel. That is, most circumstances where the topic is mentioned, talk about limited modal switching (i.e., rail to bus) and focus on single-mo de discounted fares and other deals (including the growing interest in multipurpose fare media that enable one to use a smartcard on buses, shopping, cinemas). The examples never refer to smartcards for traveling on buses and trains, which is interesting by its absence.

The studies in Appendix 1 are based on a literature review by B ooz Allan Hamilton (BAH) in 2002. Most are questionable. For example, one of the better studies by London Transport (Fairhurst 1993) found that the introduction of Travelcards boosted passenger miles in the first year by 3.83 percent-is ba sed on very aggregated time series data. We question what other control variables were included. The paper by Foote and Darwin (2001) for Chicago concludes that a 3.6 percent increase in ridership over a year when AFC was introduced is attributed to many factors but most is attributed to fare policies within a single mode (which is more reflective of where the market is). The overall growth impact (i.e., new trips) of all sources of fare changes is maximally 30 percent of 3.6 percent or 1.08 percent. Clearly much less than 10 percent suggested by the BAH review. ${ }^{25}$

The Dutch rail-taxi combination introduced in 2000 is another example of integration of two modes. One cannot infer anything about patronage growth because the new taxi services provided were rather different from those of the ordinary taxis. The train-taxis have a lower quality of service. With more passengers per taxi, one may have to wait at the railway station. Another example is the 
introduction of the standardized nationwide bus/tram/metro tick et in the Netherlands in the 1970s, enabling passengers to use the same ticke $t$ irrespective of the mode or the company providing the services. No monitoring was undertaken on the effects of its introduction at that time. Such changes tend not only to encourage integration but also produce a different price structure.

\section{Conclusions}

The arguments and evidence presented in this article suggest that the perceived gains from the reduction in the number of contract areas are likely to be illusory. If the gains in network economies are not sufficiently large to outweigh any likely loss of internal efficiency, there is a case for amalgamating contract areas to ensure that local services are not hampered by cross-contract area con straints on service delivery. Given the major focus on local service provision, opportunities to deliver appropriate cross-regional and cross-network services can be revealed and promoted by partnerships between bus operators and the regulator.

A mechanism by which the appropriate market signals are captured and made available to all relevant parties (i.e., the release of information) is required. Integrated fares as one instrument to promote network public transport activity, while having some merit, are unlikely to be a major influence on the take-up rate of cross-regional network services since they are best supplied as a single modal service through an alliance or agreement for a single operator to deliver crosscontract route-specific services where transfers are minimised if not eliminated. Then and only then might we have a chance of taking some traffic from the car market. 


\section{Appendix 1. Impact of Fares and Ticketing Integration on Patronage International Case Studies}

Source: Booz Allan Hamilton Review 2002

\section{London}

As part of a number of initiatives to increase public transport use, multimodal Travelcards were introduced for bus and underground services during early 1983. Rail was later included in the scheme with the merging of Travelcard and Capitalcard during 1989. Fairhurst (1993) sought to separately isolate patr onage impacts from changes in fares and fares integration. The first year impact from fares integration was significant with passenger miles increasing around 18 perce nt on buses, 28 percent on underground services, and 24 percent overall.

\section{Paris}

In mid 1975, the "Orange Card" was introduced in the Paris regi on. The card is a nontransferable, monthly (or yearly) season ticket that can be used on different transport modes including bus, the metro, suburban train, and various operator networks (i.e., RER, SNCF, APTR). The Orange Card has had a significant effect on patronage although the impacts on bus and metro services have been disproportionate.

\section{New York}

A major change in ticketing occurred in New York during 1997 with the introduction of the "MetroCard." A stored value card, the MetroCard can be used on the bus and the subway and is accepted by all operators. The MetroC ard had a significant effect on patronage, particularly buses. Between July 1996 and July 1997, average weekday bus ridership increased 16.9 percent and average weekend bus ridership increased 20.2 percent. The effects on the subway wer e less marked, with weekday subway ridership increasing by 2.6 percent. Overall ridership levels were at their highest since 1971 (Walker 1997).

\section{Zurich}

Prior to the introduction of integrated ticketing, Zurich was characterized by an exceptionally high level of public transport use. Schedules were coordinated on a voluntary basis with each operator having its own fares.

After the formation of the Zurcher Verkenrsverbund (ZVV), a comprehensive integrated fare and ticketing system was introduced. This invol ved the full coordi- 
nation of services and the development of a single fare system based on zonal fares. The combination of these two factors increased overall patronage by an average 12 percent in the first twp years of operation, with significan $t$ increases of 53 percent and 30 percent for feeder buses and heavy rail respecti vely (Laube 1995).

\section{Surrey}

Surrey County Council has made significant investments in several public transport schemes including the Travelwide ticket in Woking. User surveys were conducted to evaluate the performance of such schemes. Surveys revealed that the Travelwide ticket had little effect on patronage in terms of take-up by existing users (i.e., less than $2 \%$ of bus users had used the Travelwide ticket). The Travelwide ticket had limited success in generating new bus journeys. Overall, the study concluded that the multiple journey Travelwide ticket had a negligible effect on patronage (unknown author).

\section{Los Angeles}

Interoperator transfers accounted for less than 0.5 percent of total regional rides prior to the growth of fares and service integration. As service and fares integration grew, the number of passengers making multioperator trips increased. By 1994 the number of multioperator trips had increased 2 percent (i.e., 11 million boardings per year) (Carter and Pollen 1994).

\section{Chicago}

A Chicago study estimated that ridership would increase between 2 to 5 percent as a result of the introduction of automated fare collection systems (Dinning 1996).

\section{West Midlands}

One of the first major examples of integrated ticketing in Britain was the West Midlands Travelcard scheme introduced in 1972. As result of the scheme it was estimated that 7 percent more trips were being made by 1981 (White and Brocklebank 1994).I

\section{Singapore}

During 1991 to 1992, the "Farecard" system in Singapore increas ed passenger numbers by 2.5 percent. Given the increases in fare levels, thi s outcome was not anticipated (Baggaley and Fong Choon Khin 1994). 


\section{Appendix 2. Contract Area Size: The Adelaide View}

Source: Tom Wilson, Passenger Transport Board, Adelaide

Our limited experience in Adelaide was that there seemed to be little interest from tenderers in contracts with less than 30 buses (e.g., the Outer NE Transit Link Contract for 25 buses). Of course, there are many arguments abo ut bus depot size, but a large contract can easily have a number of depots.

As someone who largely designed the shape/size/boundaries of ou r Adelaide contracts, I would suggest that the most important issues are:

- Closely examining the structure of the existing route network to see how it fits together, and locate the natural breaks and boundaries

- Examining geographic boundaries

- Examining passenger travel patterns as well as having a knowledge of nonpublic transport (but potential) travel patterns

- As the main all-day public transport passenger flows in Austral ian suburbs are primarily to the City and to major regional/district centers, these centers (and major interchange points) should form the focus point s of contract areas. They can either be in the center of them, so the contract area surrounds and focuses on them, or on the boundaries of two or more contract areas, so that each adjacent contract area can focus on those centers. The trade areas of these centers is an important element in contract area design

- Allowing cross-boundary services to continue, and ensuring that new cross boundary services can be implemented by writing their possibility into the contracts. Cross boundary services should generally be allocate $d$ to the contract area within which most of the route falls

- Alternatively, very long cross boundary routes could be treated as separate "route" contracts, providing a significant number of buses is involved

- Small route groups that do not comply with all of the above should be amalgamated with the larger area contracts to allow flexibility in network planning. They could be retained if necessary where they serve an isolated area (e.g., a suburban area on one of Sydney's many peninsulas could have its own contract without impacting on flexibility) 


\section{Endnotes}

${ }^{1}$ Readers unfamiliar with the details of competitive tendering will find a useful summary in Hensher and Brewer (2001: 27-34.)

${ }^{2}$ Integrated fares is not the same as integrated ticketing. The latter refers to the technological platform within which operators provide electronic tickets.

${ }^{3}$ See Note 1.

${ }^{4}$ See Note 2.

${ }^{5}$ Although not the focus of this article, an important issue is the mechanism for distributing the fare revenue to the transport suppliers, complicated in some jurisdictions by the absence of a "flag fall" component of a bu sare for each leg of a trip (i.e., a fixed overhead charge per trip regardless of di stance traveled).

${ }^{6}$ Australasia includes Australia and New Zealand.

${ }^{7}$ An important distinction is made between contract/operator areas that are a single route in contrast to a geographical area. The distinction appears primarily a matter of shared resources such as depots and coordinated timet abling. A review of the literature failed to find a single paper addressing this issue.

${ }^{8}$ Although the firm size literature includes direct competition between firms, it also recognises situations in which firms operate as spatial monopolies as is the situation with bus operators who do not compete in the market (even though they compete with the car).

${ }^{9}$ The question not addressed in the literature on bus provision is the extent to which innovative opportunities are greater under regimes which lessen the power of the regulator in delivery of services. It may be the case th at the empirical evidence, as limited as it is, is misleading because of the failur e of incentive structures to deliver the gains which are inherent in a less constrained market. We need to understand the circumstances under which incentives can evolve and be effective. One problem with the bus industry may be that the lack of experience in managing change and/or the reticence in being innovative given a his tory of suppression of innovation is hampering the speed of taking up opportunities waiting for action. Generational inheritance, for example, which often lacks an understanding of the need to sustain wealth and survival leads to a reduction in entrepreneurial activity and hence a decline in any potential innovation. 
${ }^{10}$ The winner's curse exists when the winning operator discovers after winning that it has overpaid given the real value of the tender.

${ }^{11}$ All costs are in \$AUD, with \$AUD1.0 approximately equal to \$U.S. 0.59 .

${ }^{12}$ The internal efficiency of an organization depends on the degre e of competition it faces in so far as competition affects managerial incentives and opportunities. One way that competition sharpens incentives, and hence internal efficiency, is by permitting the relative performance of agents to be compared. Benchmarking runs the real risk of being lost with a very few operators.

${ }^{13}$ In Oslo there is currently discussion about the contract size for the future bus tenders. The authority has clearly stated that operators should be given financial incentives for passenger growth and service quality, and performance contract principles should be applied. The problem here is that there are two principalagent relationships. Firstly, there will be a contract between the city and the municipal company (Oslo Sporveier) that serves as the public transport executive (PTE). This will be a network-wide net contract that will not be tendered. Previously, this relation was subject to a performance-based subsidy, but this has been discontinued. Secondly, there will be tendered subcontracts for various packages. These are the contracts for which performance-based principles will be applied. (Both net and gross contracts are currently in use for these operations, but tendering has not yet commenced.) To ensure a sufficient number of competitors, it is expected that the PTE will want to restrict the size of cont ract areas. In practice this will mean that the tender packages will consist of a small number of routes. The Oslo network is complex and routes crisscross all over the city. Consequently, it may be difficult to implement net-cost contracts, at least without a sophisticated revenue allocation system. The alternative is a gross-cost system with quality incentives, but that is something different from the Hordaland type model, which requires a net-cost contract.

${ }^{14}$ Although not specifically related to number of operators, the issue of who owns what is very important in determining economic efficiency in service delivery. Operating franchises, such as those in Adelaide that separate investment from operating decisions, are 'bound to result in resource misallocation, manifested by overcapitalization and the production of dispensable and underutilized services' (Berechman 1993:294). Apart from the diverse goals of the owner of the assets (i.e., public sector) who promote social welfare outcomes in contrast to the commercial outcomes of the operator, the government and operator disproportion- 
ately share the overall risk since the bulk of the risk associa ted with capital investment (notably the fleet) is assumed by government. With the ris $k$ of overcapitalization greater than under single ownership (and a single comme rcial objective), the loss of economic efficiency is very real, exacerbated if the operator engages in higher risk projects than it would otherwise do so if it carrie d the full risk. This risk can, in part, be circumvented by monitoring but at a much highe $r$ level that would be required if the operator carried all the risk. It is doubtful that the government would be able to acquire all the necessary information on costs and demand without outlaying a lot of resources. Transactions costs are likely to raise questions about the value of this approach to service delivery. Under risk-sharing the notion that bidders are expected to bear the entire risk st emming from investment and operational decisions, with the face value of their bi ds serving as a sound predictor of their expected performance, evaporates.

15 "If costs of having a private firm supply the services could be reduced by means of a negotiated contract, the considerable costs of organizing a competitive bidding would be averted. Indeed .... competitive tendering scheme might in some cases be inferior to methods of contract renewal or negotiation" (Berechman, 1993, 298-99)

${ }^{16}$ Within the Sydney metropolitan area, private bus operators are some of the most cost efficient in the world. Consequently, competitive tendering is very unlikely to deliver financial benefit.

${ }^{17}$ There is a case for economies of scale in moving from a very sm all operation such as 1 to 4 buses up to about 30 buses, but over the range 30 to 100 we see almost constant returns to scale with decreasing returns to scale over 100 buses (Berechman 1993 and personal communication (July 11, 2002) with Kjell Jansson, Sweden). Fleet size is an appropriate indicator of scale, being highly correlated with other contenders such as population per square kilometer (a correlation of 0.886 for the STA contract areas). Other indicators such as area (in sq kms) has a simple correlation of -0.80 for STA areas.

${ }^{18}$ The Sydney 2000 Olympics provided valuable evidence on this ma tter (Hensher and Brewer 2003). The depot set up to coordinate bus services accommodated more than 1,000 buses, substantially larger than the largest de pot in Sydney under normal conditions (an STA depot with 250 buses). In hindsight, it was concluded that major internal efficiencies could have been obtained by having a series of smaller depots up to 150 buses. 
${ }^{19}$ We would argue that this is common in most large metropolitan areas.

20. Research by Alsnih and Hensher (2003) suggests that seniors and the elderly (i.e., individuals over 55 years old) are less inclined to use public transport where transfers are required.

${ }^{21}$ Examples of cross-regional services in the text are very weak because they do not involve picking up and dropping off in more than one contract a rea. (The CBD of Sydney is not a contract area.) This ability does not exist amo ng private operators in Sydney because of the existing contract requirements. It is suggested that the government operator (State Transit) has true cross-regional services such as Route 400 (Burwood to Bondi Junction), Route 370 (Coogee to Leichhard t), and Route L20 (City to Parramatta). Private operators have not to date de veloped strategic alliances to pick up and drop off in more than one operator's area, denying themselves of alliance revenue.

${ }^{22}$ Although the automated fare collection (AFC) system of the STA shows that one in five boardings is made by a Travelpass ticket of which 66 percent are a train+bus+ferry ticket and 32 percent are a bus-ferry ticket (with only $3 \%$ being bus only), it is unclear as to whether the ticket purchaser act ually uses more than one mode or is simply taking advantage of the attractive discou nts offered. For example, the average discount on Travelpasses is between 27 and 36 percent.

${ }^{23}$ The inequity is likely to arise from cross-subsidy to the relat ively wealthier travelers who tend to undertake the longer trips.

${ }^{24}$ The introduction of integrated fares is often in conjunction with other measures, such as increased marketing budgets to push the new tick eting and promoting bus travel, better information systems, increased bus frequencies and discounts to fares. Increased discounting would be a feature of many integrated ticketing exercises and would have an impact on ridership.

${ }^{25}$ One referee suggested, "The appendices definitely demonstrate i ncreased ridership in cases of fare integration." While not denying the absolute evidence, the text argues that the contribution of fare integration to the patrona ge increases is by no means clear and that other factors have played a role. We su pport a much more carefully constructed empirical study to establish the wider set of influence son patronage increases rather than credit it all to fares integration. 


\section{Acknowledgments}

Discussions with Erik Carlquist, Rhonda Daniels, Erne Houghton, John Stanley, Tom Wilson, Piet Rietveld, David Royle, Kjell Jansson, and Darryl Mellish are gratefully appreciated. The STA data was provided by Rhonda Daniels. The comments of two referees were especially useful. 


\section{References}

Alsnih, R., and D. A. Hensher. 2003. The mobility and accessibility expectations of seniors in an aging population. Institute of Transport Studies. The University of Sydney, March.

Baggaley, J. and M. Fong Choon Khin. 1994. Farecards: The fair way forward? Proceedings of the International Conference on Advanced Technologies in Transportation and Traffic Management. Singapore, 18-20 May.

Berechman, J. 1993. Public transit economics and deregulation policy. North Holland, Amsterdam.

Carlquist, E. 2002. Comments on this paper, personal email communication, 18 July.

Carter, D., and C. Pollen. 1994. A Joint Effort: Multi-Operator Fare Integration. California: Booz Allen and Hamilton.

Daniels, R. 2002. Comments on Cost Differences, personal commu nication, 31 May.

DeBorger, B., and K. Kerstens. 2000. The performance of bus-transit operators. In Handbook of transport modelling. D. A. Hensher and K. J. Button, K.J., eds.: 577-595. Handbooks in Transport, Volume 1. Oxford: Pergamon Press.

Dinning, M. 1996. The business case for smartcards in public transit systems. Washington DC: U.S. Department of Transportation.

Fairhurst, M. H. 1993. Fares and ticketing policy in London: From Travelcards to smartcards. London Transport. Research Report R273. LT Planning Department. July.

Foote, P., and S. Darwin. 2001. Impacts of transit fare policy initiatives under an automated fare system. Transportation Quarterly 54 (3): 51-66.

Hay, D., and J. Vickers. 1987. The economics of market dominance. Oxford: Basil Blackwell.

Hensher, D. A., and A. M. Brewer. 2001 Transport: An economics and management perspective. Oxford: University of Oxford Press.

Hensher, D. A. and A. M. Brewer. 2003. Going for gold at the Sydney Olympics: How did transport perform? Transport Reviews 22(4): 381-399. 
Hensher, D. A., and E. Houghton. 2003. Performance-based contracts for the bus sector: Delivering social and commercial value for money. Transportation Research B.

Hensher, D.A., and J. K. Stanley. 2003 Performance-based contracts and/or competitive tendering in urban bus service provision? Transportation Research A.

Hibbs, J. 2000. Transport policy: The myth of integrated planning. Hobart Paper 140. London: Institute of Economic Affairs.

Laube, F. 1995. Fully integrated transport networks: An international perspective on applied solutions. Paper presented at Ticketing Technologies Conference. Darling Harbour. 5-6 April.

Preston, J. and D. van de Velde. 2002 Competitive tendering of public transport: theme A. Transport Reviews (Thredbo 6 workshop report).

Tye, W. B. 1987 Encouraging cooperation among competitors. New York: Quorum Books.

Unknown Author. 1993. An Investigation into the effectiveness of public transport initiatives. Prepared for Surrey County Council, Surrey.

Walker, T. 1997. Recent developments in automatic fare collection. Southern Cubic Pty Ltd.

Williamson, O. E. 1987. Antitrust economics. Oxford: Basil Blackwell.

White, P., and P. Brocklebank. 1994. Urban travel and the smartcard. Paper presented at Smartcard Conference. February.

\section{About the Author}

David Hensher (Davidh@its.usyd.edu.au) is professor of management and director of the Institute of Transport Studies: The Australian Key Centre of Teaching and Research in Transport Management. He is a chaired professor in the faculty of economics and business at the University of Sydney.

Prof. Hensher is a fellow of the Academy of Social Sciences in Australia, immediate past president of the International Association of Travel Behaviour Research, and a vice-chair of the International Scientific Committee of the World Conference of Transport Research. He is on the editorial boards of 10 of the leading transport journals and area editor of Transport Reviews. He has published extensively (more 
than 270 papers) in the leading international transport journal $s$ and key journals in economics and has authored five books. His most recent books are Transport: An Economics and Management Perspective (with Ann Brewer; Oxford University Press), and Stated Choice Methods (with Jordan Louviere and Joffre Swait; Cambridge University Press.) 